\title{
De Klockner a Total: la reivindicación de la aplicación de las fuentes del derecho internacional en el arbitraje internacional de inversión extranjera
}

\author{
Walter Arévalo-Ramírez* \\ Laura Victoria García Matamoros**
}

\begin{abstract}
RESUMEN
El presente artículo analiza la aplicabilidad de las fuentes del derecho internacional y los principios de derecho en el arbitraje de inversiones, por medio del notorio vuelco de los tribunales arbitrales de inversión extranjera en el CIADI, en materia de derecho aplicable, con especial atención a un período de cambio entre 2000 y 2010 entre los laudos Wena Hotels (2000-2002) y Total (2010) cuya tendencia se extiende hasta la actualidad en el CIADI, donde los tribunales cada vez más deciden aplicar a las controversias entre inversionista y Estado las distintas fuentes de derecho internacional público y los principios generales del derecho, más allá de los instrumentos privados, tanto en procedimientos originarios como en procedimientos de anulación. El artículo analiza la posibilidad de aplicar el derecho internacional como norma principal en los procedimientos ante el CIADI, la aplicación por parte de los tribunales del CIADI tanto de costumbres internacionales en materia de responsabilidad internacional del Estado, de principios internacionales para darle contenido a las garantías sustantivas y a las protecciones a los inversionistas y a las reparaciones concedidas por los laudos.
\end{abstract}

Arbitraje internacional de Inversiones; Derecho Internacional Público; Costumbre Internacional

\section{From Klockner to Total: The assertion of the applicability of the sources of international law in International Foreign Investment arbitrations}

\section{Abstract}

This article analyzes the applicability of the sources of international law and the principles of law in international investment arbitration, through the notorious change in point of view of the

* Abogado de la Universidad del Rosario, Colombia. Magíster en Derecho internacional, Stetson University College of Law, Estados Unidos. Doctor en Derecho, Universidad del Rosario, Colombia. Profesor Principal de carrera académica de la Facultad de Jurisprudencia, Universidad del Rosario, Colombia. ORCID: https://orcid.org/0000-0002-8501-5513.Correo electrónico: walter.arevalo@urosario.edu.co

** Abogada de la Universidad del Rosario, Colombia. Doctora en Derecho, Universidad Externado de Colombia. Vicedecana y profesora titular de carrera académica de la Facultad de Jurisprudencia, Universidad del Rosario, Colombia. ORCID: https://orcid.org/0000-0003-0270-9315. Correo electrónico: laura.garcia@ urosario.edu.co

Artículo recibido el 12.4.2020 y aceptado para su publicación el 28.4.2021. 
ICSID foreign investment panels, in matters of applicable law, with a special period of change between 2000 and 2010 between the Wena Hotels (2000-2002) and Total (2010) awards, a trend which extends to the present, in which ICSID arbitral proceedings have increasingly decided to apply to investor-State disputes the different sources of public international law and the general principles of law, both in original proceedings and in annulment proceedings, despite the private instrument. The article analyzes the possibility of applying international law as the main controlling rule in ICSID proceedings, the application by ICSID arbitral tribunals of both international customary law regarding international responsibility of the State, the application of international law principles to give content to the substantive protections to investors and to the reparations granted by the awards.

Foreign investment arbitration; Public International Law; International Customary Law

\section{INTRODUCCIÓN}

$\mathrm{E}$ 1 presente artículo $^{1}$ analiza la aplicabilidad de las fuentes del derecho internacional y los principios de derecho en el arbitraje de inversiones, mediante el notorio vuelco de los tribunales arbitrales de inversión extranjera en el CIADI (Centro Internacional para el Arreglo de Diferencias Relativas a Inversiones), en materia de derecho aplicable, con atención especial al período de cambio entre 2000 y 2010 con los laudos Wena Hotels (2000-2002) y Total ${ }^{2}$ (2010) cuya tendencia se extiende hasta la actualidad en los tribunales del CIADI que cada vez más deciden aplicar a las controversias entre inversionista y Estado las distintas fuentes de derecho internacional público y los principios generales del derecho, tanto en procedimientos originarios como en procedimientos de anulación ${ }^{3}$.

Esta reivindicación de la aplicabilidad del derecho internacional público en arbitrajes de inversión parece superar la anterior práctica de los tribunales arbitrales, que centraba el derecho aplicable en el dispuesto en el instrumento de la inversión y que remitía al derecho elegido por las partes, constituido usualmente por el derecho nacional de uno de los dos Estados o una mezcla de las normas domésticas de las dos partes ${ }^{4}$ o el instrumento privado.

En la actualidad y gracias a varias decisiones, hito que será analizado en el presente artículo, los tribunales arbitrales reconocen la aplicabilidad directa ${ }^{5}$ y no subsidiaria de los principios generales del derecho y las fuentes del derecho internacional público a los casos que les son sometidos, a la par o incluso supliendo vacíos del derecho reconocido por el instrumento que protege la inversión.

${ }^{1}$ La presente investigación es un producto de los avances de investigación dentro del Proyecto "Derecho Internacional Económico" del grupo de investigación en derecho internacional de la Facultad de Jurisprudencia de la Universidad del Rosario.

2 Delaney, 2007, p. 10

${ }^{3}$ Verhoosel, 2008, pp. 119-154.

${ }^{4}$ SCHILL, 2010.

${ }^{5}$ MCLaChlan, 2008, pp. 361-401. 
El artículo también analiza las tendencias doctrinarias que han emergido para reivindicar al arbitraje internacional de inversiones como un procedimiento esencialmente constituido por normas de derecho internacional público, producto de relaciones interestatales, entre verdaderos sujetos del derecho internacional, que posteriormente facultan el ius standi de sujetos no estatales como lo son los inversionistas, permitiéndoles presentarse ante procedimientos internacionales demandando a Estados y cuya naturaleza jurídica no puede escapar al dominio de las fuentes del derecho internacional público por más importancia que tenga el instrumento privado en el arbitraje.

La doctrina reciente en la materia busca superar la errónea creencia de que este procedimiento inversionista-Estado no es un procedimiento de derecho internacional público ${ }^{6}$ y tiende a asumirlo como un procedimiento de derecho económico y privado, una postura que fue adoptada por muchos tribunales de arbitrajes en la historia del CIADI, sustentada en la aplicabilidad al caso de los instrumentos "privados" entre el inversionista y el Estado (contratos, acuerdos) reconocidos o emanados de los TBI.

Este fenómeno ha sido analizado recientemente por autores como Salacuse, que han edificado un framework de normas contractuales, nacionales e internacionales, correlativas entre ellas, que crean distintos regímenes para la protección de inversiones, pero cuya coordinación y efectividad final solo puede estar en manos de la correcta aplicación de un marco común internacional, donde fuentes como los principios y la costumbre internacionales sean plenamente aplicables, tanto para darle contenido a las protecciones sustantivas pactadas en los tratados, como para suplir los vacíos del derecho nacional en todo tipo de asuntos ${ }^{7}$.

Esta postura que desligaba al arbitraje de inversiones del conjunto de fuentes del derecho internacional, es parte del sustento de las críticas que se han realizado en los últimos años a varios paneles arbitrales ${ }^{8}$ que en sus laudos en situaciones complejas, como aquellas en que los Estados invocaban los derechos humanos, el orden público o defensas típicas del derecho internacional (fuerza mayor, estado de necesidad), ponían en segundo lugar los principios generales del derecho y las fuentes del derecho internacional clásico como la costumbre internacional o principios generalmente aceptados por los Estados y privilegiaban acuerdos privados, que podían derogarlos o contradecirlos.

Tal tendencia a su vez alejó las relaciones inversionista-Estado de elementos esenciales del orden jurídico internacional como los derechos humanos o el orden público internacional ${ }^{9}$. Obras como la de Chin Leng Lim, Jean Ho y Martins Paparinskis en 2018 han recientemente reiterado que, por un lado, la naturaleza internacional del arbitraje de inversiones se desprende no solo de su concepción convencional mediante tratados, sino de sus fundamentos históricos como la protección diplomática. Igualmente, Lim, Ho y Paparinskis han construido, para explicar el anteriormente mencionado debate

\footnotetext{
${ }^{6}$ Alvarez, 2011.

${ }^{7}$ Salacuse. 2013, p. 315.

${ }^{8}$ FrANCK, 2004, p. 1521.

9 FRY, 2007, p. 77.
} 
acerca de la ley aplicable, la noción de composite national-international law ${ }^{10}$, como una unión indisoluble del que ellos llaman el interplay of laws que implica el arbitraje de inversiones, donde algunas reclamaciones pueden ser fácilmente resueltas con referencia al derecho nacional y contractual, pero otras, por el contrario, obligatoriamente remiten al derecho internacional y sus principios.

Justamente esta concepción de la naturaleza privada y alejada del orden e interés público que se le ha criticado al arbitraje de inversiones, es en parte una crítica a su naturaleza arbitral, como procedimiento que aleja las controversias de las cortes nacionales y admite altos grados de privacidad cuando lo solicitan las Partes, pero en realidad, la separación o no del arbitraje de inversiones del orden público internacional y del derecho internacional no es culpa de su esencial arbitral, sino de los debates acerca del derecho aplicable, en términos de Christian Tiejte:

Uno de los mitos más importantes a este respecto es la idea de que el arbitraje de inversión es llevado a cabo por tribunales "privados". El arbitraje de inversión generalmente se basa en una cláusula de arbitraje que forma parte de un tratado de inversión entre dos o más Estados. Por lo tanto, el arbitraje de inversión es por definición un arbitraje público o al menos algún tipo de arbitraje sui generis. Con respecto a los intereses públicos en este tipo de arbitraje, el problema no es el arbitraje; Los problemas que pueden surgir en este contexto son una cuestión de derecho sustantivo aplicable. Es la ley aplicable respectiva la que debe reflejar los intereses públicos ${ }^{11}$.

Para analizar la reivindicación del derecho internacional público como derecho aplicable y como sustento jurídico del derecho internacional de la inversión extranjera, en el presente artículo, en primer lugar, se estudia el verdadero contenido y alcance de la expresión derecho aplicable en el ámbito del CIADI y los aportes de los laudos recientes a la ampliación de las normas aplicables más allá del acuerdo entre el inversionista y el Estado. Posteriormente, se analizan los casos que han sido hito, especialmente en el período elegido de cambio, de la reivindicación de la aplicabilidad de las fuentes y principios de derecho internacional público en los procedimientos de arbitraje de derecho internacional de la inversión extranjera.

Finalmente, el artículo analiza los principios generales del derecho (como parte de las fuentes del derecho internacional público, pero también reconocidos por los sistemas jurídicos domésticos) que han sido utilizados recientemente en el arbitraje internacional de inversiones para suplementar el derecho sustantivo en materia de inversión extranjera y para establecer el alcance de nociones básicas del derecho al momento de ser traídas a estos arbitrajes, como el contenido de las reparaciones ${ }^{12}$, o en casos de

\footnotetext{
${ }^{10}$ Lim, Ho y PAPARINSKis, 2018, p. 156.

11 Tietje, 2016.

12 Schreuer, 2005, pp. 1-17.
} 
vaguedad, darle contenido a expresiones como "trato justo y equitativo" o "expectativas legítimas" 13 usualmente poco explicitadas en instrumentos como los TBI o los contratos inversionista-Estado.

\section{Noción JURISDICCIONAL Y SUSTANTIVA: DOS DEFINICIONES DE “DERECHO APLICABLE” EN EL CONTEXTO DEL CIADI Y LOS PRINCIPIOS DEL DERECHO INTERNACIONAL PÚBLICO QUE GOBIERNAN EL DERECHO APLICABLE EN MATERIA JURISDICCIONAL}

En primer lugar, es necesario realizar una distinción entre la definición del concepto de "derecho aplicable" para la competencia del CIADI (Art. 25 (1), (2) y (4). del Convenio del CIADI) y el significado de "derecho aplicable" para la solución sustantiva de la controversia (Artículo 42 (1) del Convenio), pues es en esta segunda en donde se busca la aplicación de las fuentes y principios generales del derecho internacional en los procedimientos. En materia de competencia, el Convenio, en el Art. 25 (1), (2) indica:

\section{Artículo 25}

(1) La jurisdicción del Centro se extenderá a las diferencias de naturaleza jurídica que surjan directamente de una inversión entre un Estado Contratante (o cualquiera subdivisión política u organismo público de un Estado Contratante acreditados ante el Centro por dicho Estado) y el nacional de otro Estado Contratante y que las partes hayan consentido por escrito en someter al Centro. El consentimiento dado por las partes no podrá ser unilateralmente retirado.

(2) Se entenderá como "nacional de otro Estado Contratante":

(a) toda persona natural que tenga, en la fecha en que las partes consintieron someter la diferencia a conciliación o arbitraje y en la fecha en que fue registrada la solicitud prevista en el apartado (3) del Artículo 28 o en el apartado (3) del Artículo 36, la nacionalidad de un Estado Contratante distinto del Estado parte en la diferencia; pero en ningún caso comprenderá las personas que, en cualquiera de ambas fechas, también tenían la nacionalidad del Estado parte en la diferencia; y

(b) toda persona jurídica que, en la fecha en que las partes prestaron su consentimiento a la jurisdicción del Centro para la diferencia en cuestión, tenga la nacionalidad de un Estado Contratante distinto del Estado parte en la diferencia, y las personas jurídicas que, teniendo en la referida fecha la nacionalidad del Estado parte en la diferencia, las partes hubieren acordado atribuirle tal carácter, a los efectos de este Convenio, por estar sometidas a control extranjero. (...)

Si bien desde la óptica del artículo 25 del Convenio del CIADI es derecho aplicable en materia jurisdiccional, el escrito de sometimiento al centro, los términos de los

\footnotetext{
${ }^{13}$ GAZZINI, 2012.
} 
instrumentos que expresan el consentimiento de las partes al arbitraje del CIADI y las normas aplicables de nacionalidad, entendidos ambos elementos como criterios de competencia en cuestiones de admisibilidad, resulta más relevante la selección del derecho aplicable por las partes que se realiza por virtud del artículo 42 del Convenio del CIADI, y que tiene efectos en el fondo de la disputa. Ese es el verdadero escenario del debate del presente artículo respecto de la posibilidad de aplicar los principios generales del derecho y el derecho internacional público en la solución de los casos sometidos al Centro:

Artículo 42 (1). El Tribunal decidirá la diferencia de acuerdo con las normas de derecho acordadas por las partes. A falta de acuerdo, el Tribunal aplicará la legislación del Estado que sea parte en la diferencia, incluyendo sus normas de derecho internacional privado, y aquellas normas de derecho internacional que pudieren ser aplicables. (2) El Tribunal no podrá eximirse de fallar so pretexto de silencio u oscuridad de la ley. (3) Las disposiciones de los precedentes apartados de este Artículo no impedirán al Tribunal, si las partes así lo acuerdan, decidir la diferencia ex aequo et bono.

La interacción de estas dos normas y el significado de derecho aplicable entre ellas requiere algunos comentarios. En primer lugar, la selección del derecho aplicable para el fondo de la disputa no tiene efectos en la competencia de los paneles del CIADI y solo se predica por el fondo de la controversia. Esta distinción ha sido reiterada por los laudos del CIADI, especialmente para excluir normas nacionales (parte del derecho aplicable emanado de la legislación nacional en el contexto del artículo 42), que se han querido invocar en el contexto del artículo 25 para evitar el arbitraje y someter la disputa a la jurisdicción nacional, como ocurrió en el caso CMS:

El Comité recuerda en primer lugar que la jurisdicción del Centro no está determinada por el Artículo 42 (1) del Convenio del CIADI, sino por el Artículo 25. La competencia del Tribunal se rige por los términos de los instrumentos que expresan el consentimiento de las partes al arbitraje del CIADI, es decir, en el presente caso el TBI Argentina-Estados Unidos. En consecuencia, como lo decidió correctamente el Tribunal, "las disposiciones jurisdiccionales aplicables son solo las de la Convención y el TBI, no las que podrían surgir de la legislación nacional. La ley argentina es irrelevante en este sentido, como se reconoce en el laudo y en muchas otras decisiones ${ }^{14}$.

En segundo lugar, hay dos principios generales del derecho, reconocidos como principios aplicables en el derecho internacional, que guían la interpretación del artículo 25 del Convenio. Estos son el principio de irretroactividad y el principio de lex specialis, pues bajo el reglamento del Convenio, los asuntos de entrada en vigor de los instrumentos

\footnotetext{
${ }^{14}$ CMS Gas Transmission Co. c Argentina., CIADI No. ARB/01/8, Decision on Annulment, para. 66-68
} 
de sometimiento al Centro son un debate de naturaleza jurisdiccional que debe constatar el tribunal arbitral al inicio de los procedimientos. El artículo 68 (2) del Convenio establece que este entra en vigor treinta (30) días después de la fecha del depósito del instrumento de ratificación, aceptación o aprobación del Estado correspondiente ${ }^{15}$.

En el contexto procesal del CIADI, la entrada en vigor del Convenio no tiene los mismos efectos que la entrada en vigor del TBI particular que somete la inversión al Centro. Esto implica fenómenos como la posibilidad de la protección de la inversión futura (un TBI antecedido por el Convenio) o la posibilidad de proteger inversiones y controversias previas a la entrada en vigor del TBI mediante su inclusión en la competencia del centro por expresa estipulación de las Partes.

Según la regla general, serán protegidas por la cláusula de competencia del CIADI que incluya un TBI, todas aquellas inversiones previas pero vigentes ${ }^{16}$, y futuras inversiones una vez firmado el TBI. Frente a controversias previas a la entrada en vigor del Convenio del CIADI y del TBI, a causa del principio de irretroactividad de los tratados reconocido por la Convención de Viena sobre el Derecho de los Tratados, en principio, no habría competencia del Centro.

Si bien esta es la regla general, en aplicación del principio, lex specialis ${ }^{17}$, ampliamente reconocida como aplicable en derecho internacional público (como ocurre con la resolución A/56/83 en materia de responsabilidad internacional), es posible que los Estados contratantes estipulen cuáles controversias específicas desean incluir o excluir de la aplicación del Convenio, incluyendo la capacidad de cobijar inversiones con controversias previas a la entrada en vigor del Convenio. Esta interpretación es muestra de que el derecho internacional gobierna el debate de la jurisdicción en el CIADI:

Artículo 25(4): Los Estados Contratantes podrán, al ratificar, aceptar o aprobar este Convenio o en cualquier momento ulterior, notificar al Centro la clase o clases de diferencias que aceptarían someter, o no, a su jurisdicción. El Secretario General transmitirá inmediatamente dicha notificación a todos los Estados Contratantes. Esta notificación no se entenderá que constituye el consentimiento a que se refiere el apartado (1) anterior.

Artículos como el 25(4) del Convenio y la condición de lex specialis de estos sometimientos, son un ejemplo adicional de la naturaleza de derecho internacional público de estos arbitrajes, en tanto es el derecho internacional público el que ha reconocido la prevalencia del lex specialis frente a reglas generales catalogadas como ius dispositivum que permiten a las partes elaboraciones de acuerdos posteriores o específicos que se aparten de la regla general de jurisdicción o fondo, como lo reconociera la Corte Internacional de

\footnotetext{
15 Arévalo, 2019.

16 Arévalo y García, 2016, pp. 243-278.

${ }^{17}$ LOWENFELD, 2003, p. 123.
} 
Justicia en los casos de la Plataforma Continental del Mar del Norte y Derecho de Paso, que establecen como aplicable el principio de lex specialis en derecho internacional ${ }^{18}$.

Igualmente, casos donde la competencia ha emanado de instrumentos privados o del derecho nacional, también han implicado que los paneles interpreten la jurisdicción en aplicación del derecho internacional ${ }^{19}$. En el caso SPP v. Egypt (resaltable además porque el panel estaba presidido por el internacionalista latinoamericano Eduardo Jiménez de Aréchaga), aun cuando la jurisdicción del Centro emanaba directamente del derecho interno -ley egipcia acerca de protección de inversiones-, la interpretación de las causales o formas de consentimiento para someter la disputa al CIADI se realizó según el derecho internacional, especialmente el derecho de los tratados en aplicación del Convenio, interpretando que el derecho interno, más que una norma aplicable en materia de jurisdicción, era un acto unilateral que generaba obligaciones en derecho internacional que debían ser interpretadas de acuerdo con las reglas que en derecho internacional gobiernan este tipo de actos.

The issue is whether certain unilaterally enacted legislation has created an international obligation under a multilateral treaty. Resolution of this issue involves both statutory interpretation and treaty interpretation. Also, to the extent that Article 8 is alleged to be a unilateral declaration of acceptance of the Centre's jurisdiction, subject to reciprocal acceptance by a national of another Contracting State, the Tribunal must also consider certain aspects of international law governing unilateral juridical acts. This is a subject that has received considerable attention in the jurisprudence of both the Permanent Court of International Justice and the International Court of Justice in connection with declarations under the so-called "Optional Clause" of the Courts' statutes. As the International Court of Justice observed in its judgment on jurisdiction in the Military and Paramilitary Activities in and Against Nicaragua case (quoting from its earlier judgment on jurisdiction in the Nuclear Tests cases): It is well recognized that declarations made by way of unilateral acts, concerning legal or factual situations, may have the effect of creating legal obligations. Declarations of this kind may be, and often are, very specific. When it is the intention of the State making the declaration that it should become bound according to its terms, that intention confers on the declaration the character of a legal undertaking, the State being thenceforth legally required to follow a course of conduct consistent with the declaration. (I.C.J. Reports 1984, p. 418.) Thus, in deciding whether in the circumstances of the present case Law No. 43 constitutes consent to the Centre's jurisdiction, the Tribunal will apply general principles of statutory interpretation taking into consideration, where appropriate, relevant rules of treaty interpretation and principles of international law applicable to unilateral declarations ${ }^{20}$.

${ }^{18}$ ICJ, North Sea Continental Shelf cases, Reports 1969, p. 42, para 72. it is well understood that, in practice, rules of general international law can, by agreement, be derogated from in particular cases or as between particular parties.

19 SCHrEuEr, 2007.

${ }^{20}$ Southern Pacific Properties (Middle East) Limited v. Arab Republic of Egypt ICSID Case No. ARB/84/3. Para.61. 
Adicionalmente, la investigación arroja el curioso procedimiento en materia de interpretación del instrumento de jurisdicción que se presentó en el caso CSOB v. Slovakia, en el que la jurisdicción se basaba en un contrato entre las partes que se refería a una cláusula de jurisdicción del CIADI presente en un TBI que nunca entró en vigor (República Checa-Eslovaquia).

El panel interpretó que la referencia al TBI en el contrato implicaba la voluntad de las partes de incorporar la cláusula de jurisdicción del CIADI en el mismo, bajo esta premisa, el panel indicó que el acuerdo sobre el consentimiento y el acuerdo privado se debían interpretar según el derecho internacional y no solamente como un contrato interpretado bajo el derecho interno:

35. The question of whether the parties have effectively expressed their consent to ICSID jurisdiction is not to be answered by reference to national law. It is governed by international law as set out in Article 25(1) of the ICSID Convention.

56. Respondent also contends that even if the BIT is held to be applicable, its disputesettlement mechanism under Article 8 can be invoked only by means of a joint submission of the dispute by the parties either to an ICSID arbitration tribunal or to a tribunal established under the UNCITRAL arbitration rules. Since Claimant has not sought ICSID arbitration jointly with Respondent, the latter submits that the requirements of Article 8 of the BIT have not been satisfied ${ }^{21}$.

\section{EL DERECHO INTERNACIONAL PÚBLICO COMO DERECHO APLICABLE} AL FONDO DE LA CONTROVERSIA Y SU REIVINDICACIÓN EN EL ARBITRAJE DE LA INVERSIÓN EXTRANJERA: LAUDOS QUE REDEFINEN EL ALCANCE Del Art. 42 Del Convenio CIADI

El problema de la aplicación del derecho internacional público por parte de los paneles del CIADI en el fondo de la controversia, bien sea de forma directa, de forma subsidiaria o concomitante frente al instrumento elegido por las partes, o su no aplicación, ha girado en los laudos del Centro alrededor de la interpretación del Art. 42, que ha trasegado de interpretaciones textuales a posiciones que reivindican el rol integrador y necesario del derecho internacional en arbitrajes más recientes.

La interpretación textual del Art. 42, que fue la regla de las primeras épocas del Centro indica que el Tribunal debe respetar una jerarquía ${ }^{22}$ en los siguientes términos: primero aplicar las normas de derecho acordadas por las partes y en caso de que no exista un acuerdo en la materia, aplicar la legislación del Estado receptor de la inversión, dentro del cual, podrá identificar sus normas de derecho internacional privado y aquellas normas

\footnotetext{
${ }^{21}$ Ceskoslovenska Obchodni Banka, a.s. v. The Slovak Republic ICSID Case No. ARB/97/4 paras.35-60.

22 Gaillard, 2003, pp. 375-411.
} 
de derecho internacional que ese Estado reconozca o incorpore y que sean aplicables a la controversia, con la prohibición de declarar un non liquet por falta de derecho aplicable.

La práctica más reciente de los procedimientos ante el CIADI, con un período especial de cambio entre 2000 y 2010 entre los laudos Wena Hotels (2000-2002) y Total (2010) que serán comentados junto con otros a lo largo del presente artículo, ha demostrado que los tribunales han superado la interpretación de que el derecho internacional es subsidiario, llegando a aplicar directamente todas las reglas de derecho internacional relevantes, en todo tipo de fuentes, tanto cuando las partes han hecho una elección expresa del derecho aplicable ${ }^{23}$ como cuando no existe y aparentemente el derecho internacional se aplicaría en forma subsidiaria ${ }^{24}$. A su vez, independientemente del lugar dado por los paneles al derecho internacional, en el arbitraje de inversiones, el derecho internacional es constantemente aplicado para resolver elementos de las controversias que involucran cuestiones de soberanía, nacionalidad, responsabilidad internacional del Estado por hechos ilícitos, costumbre y protección diplomática ${ }^{25}$.

La experiencia reciente de los paneles del CIADI da cuenta de que en aplicación de normas y principios del derecho internacional público ${ }^{26}$ los paneles han extendido el derecho aplicable más allá de lo explicitado en el TBI y han invocado efectivamente instituciones clásicas del derecho internacional como buena fe, fraude a la ley, Nemo auditur propiam turpitudinem allegans, Pacta Sunt Servanda, estoppel, enriquecimiento sin causa $^{27}$, la obligación de compensación en todo caso de nacionalización, debido proceso y cosa juzgada ${ }^{28}$, incluyendo el régimen constituido por las reglas de la Convención de Viena sobre el Derecho de los Tratados y han profundizado el diálogo jurisprudencial al no solo citar los laudos de otros tribunales bajo la jurisdicción del CIADI sino otros tribunales internacionales como criterios interpretativos.

En la búsqueda de esta aplicabilidad de las normas de derecho internacional, aparte del análisis de laudos relevantes, la doctrina reciente ha desarrollado varios aportes desde los cuales partir, como los trabajos de Emmanuel Gaillard ${ }^{29}$, que se ha enfocado en el contenido y el alcance de la expresión "derecho internacional" en el Art. 42 del Convenio CIADI, explorando la posibilidad de aplicar los principios de derecho internacional público a las controversias de manera directa y no meramente subsidiaria.

\footnotetext{
23 Arévalo y Garcia, 2016, pp. 24-278.

${ }^{24}$ SCHreuer, 2009, p. 607

25 Arévalo, 2020, pp. 120.

${ }^{26}$ Chukwumerije, Okezie, 1997, pp. 79-101.

27 Arévalo y Garcia, 2016, pp. 243-278.

${ }^{28}$ SCHREUER, 2009, pp. 608-609.
}

29 El 1ero de abril de 2021, durante la edición del presente artículo, tuvo lugar el lamentable fallecimiento del Profesor Emmanuel Gaillard. Los autores se suman a las condolencias del mundo arbitral, compartiendo el siguiente homenaje: Fernández-Arroyo, Diego y Senegacnik, Alexandre. "Hommage à Emmanuel Gaillard, professeur de droit international et lumière de l'arbitrage du xxie siècle" en "Accueil - SciencePo École de Droit”. 2021. Disponible en https://www.sciencespo.fr/ecole-de-droit/fr/actualites/ hommage-emmanuel-gaillard-professeur-de-droit-international-et-lumiere-de-l-arbitrage-du-.html. Consultado el 14 de abril de 2021. 
Dos elementos esenciales del debate han sido considerados por la literatura: 1) el significado y contenido de la expresión derecho internacional público en el contexto del arbitraje de inversión extranjera y 2) si el derecho internacional, al ser mencionado por el Art. 42 aparentemente como un derecho subsidiario, se debe aplicar solo en caso de vacíos del derecho del Estado receptor de la inversión o situaciones no plenamente definidas por los instrumentos privados, o si contrario a esta interpretación, es un derecho sustantivo de aplicación directa cuyas normas sean plenamente aplicables, incluso cuando contradicen al derecho doméstico del Estado receptor.

Gaillard constata mediante los travaux preparatoires del Convenio CIADI que el significado de "derecho internacional" en la segunda oración del Artículo 42 (1) corresponde a lo entendido como "derecho internacional general" aplicado por los tribunales internacionales interestatales, según el artículo 38 del Estatuto de la Corte Internacional de Justicia ${ }^{30}$. Durante la negociación de la Convención de Washington, en el último borrador del Artículo 42 (1) se discutió que "[l] El término 'derecho internacional" tal como se usa en este contexto debe entenderse en el sentido que se le otorga por el artículo 38 (1) del Estatuto de la Corte Internacional de Justicia, teniendo en cuenta el hecho de que el artículo 38 fue diseñado para aplicarse a controversias interestatales".

Esta interpretación del concepto de derecho internacional, implica que a las controversias internacionales donde se active el Art. 42, bien sea en la aplicación del derecho aplicable elegido por las partes o aplicando el "derecho internacional" de forma subsidiaria o directa, le serán aplicables no solo las normas de derecho internacional reconocidas por el derecho del Estado receptor o el TBI, sino todas las a) convenciones internacionales, ya sean generales o particulares, que establecen reglas expresamente reconocidas por los Estados contendientes; b) la costumbre internacional, como evidencia de una práctica general aceptada c ) los principios generales de derecho y los medios auxiliares de interpretación que constituyen las decisiones judiciales y la doctrina, como indica el Art. 38 (1) del Estatuto de la CIJ.

Gaillard desarrolla que mediante esa definición amplia de derecho internacional que no solo se limita al TBI o a normas de derecho internacional que resuelvan lagunas del derecho interno aplicable, la segunda oración del Artículo 42 (1), y la redacción "y las normas de derecho internacional que sean aplicables" deben entenderse como una habilitación para que el tribunal arbitral determine las normas sustantivas aplicables de derecho internacional de acuerdo con las fuentes aceptadas en el Artículo 38 del Estatuto de la Corte Internacional de Justicia ${ }^{31}$. Esta interpretación del derecho internacional como todo un sistema jurídico con un sistema de fuentes plenamente aplicable, supera y corrige lo que algunos tribunales arbitrales decidieron durante años, al aplicar el derecho internacional general, solo en caso de un vacío o error en el derecho del Estado receptor de la inversión y únicamente cuando la elección de las partes ha sido previamente aplicada y un vacío insuperable ha aparecido en las normas aplicables al litigio.

\footnotetext{
30 Gaillard, 2003, pp. 375-411.

31 Gaillard, 2003, pp. 375-411.
} 
La subsidiariedad del derecho internacional en el arbitraje de inversiones, como complementador del derecho del Estado receptor de la inversión en caso de lagunas, es una lectura literal y superficial de la norma que desconoce su propósito y alcance evidente en los trabajos preparatorios, que se ha repetido en la "jurisprudencia" de los paneles, que lleva a la errónea conclusión de que aun en ausencia de una elección de derecho aplicable por las partes en la controversia de inversión sometida a un arbitraje internacional de inversiones, el papel del derecho internacional se limita a complementar el derecho nacional del Estado receptor por la existencia de lagunas en la materia o para corregirlo cuando sea incompatible con una norma aplicable del derecho internacional, por ejemplo, acerca de normas esenciales en materia de tratados ${ }^{32}$.

Bajo esta lectura errónea, se le ha dado a la palabra "y" en la segunda oración del Artículo 42 (1) un significado similar a: “y, en caso de lagunas, o si la ley del Estado contratante es incompatible con el derecho internacional”.

Aquel papel subsidiario del derecho internacional, de ser considerado únicamente invocable ante las lagunas del derecho elegido por las partes, reduciendo su condición de sistema jurídico completo y directamente aplicable al fondo de la controversia, fue impulsada por el Comité ad hoc en el caso Klockner ${ }^{33}$ en los años ochenta:

"El artículo 42 de la Convención de Washington establece que "en ausencia de un acuerdo entre las partes, el Tribunal aplicará la ley del Estado contratante parte en la disputa ... y los principios del derecho internacional que sean aplicables”. Esto otorga a estos principios (tal vez omitiendo los casos en los que se debe determinar si la legislación nacional se ajusta al derecho internacional) una doble función, es decir, complementaria (en el caso de una "laguna" en la ley del Estado), o correctiva, en caso de que la ley del Estado no se ajuste en todos los puntos a los principios del derecho internacional. En ambos casos, los árbitros pueden recurrir a los 'principios del derecho internacional' solo después de haber consultado y establecido el contenido del derecho del Estado parte en la disputa (que no puede reducirse a un principio, ni siquiera uno básico) y después de haber aplicado la norma pertinente de la ley del Estado.

Por lo tanto, el artículo 42 (1) claramente no permite al árbitro basar su decisión únicamente en las "reglas" o "principios del derecho internacional" 34 .

Con el incremento de las disputas ante el Centro en los años 2000, paneles más recientes han reiterado que la expresión relativa al derecho internacional en el Art. 42 y la aplicación de sus fuentes por parte de los tribunales arbitrales en el fondo, implica

\footnotetext{
32 Gaillard, 2003, p. 373.

33 Galllard, 2003, pp. 371-374.

${ }^{34}$ Klockner c. Cameroon, Ad Hoc Committee Decision, 19852 ICSID Rep. 95 (1994) para. 122.
} 
darle un rol protagónico, como indica originalmente el espíritu de las negociaciones del Convenio y la naturaleza interestatal del arbitraje internacional ${ }^{35}$.

En decisiones como Wena Hotels Limited ${ }^{36}$ (fondo y anulación), corresponde darle al derecho internacional el papel de un derecho sustantivo autónomo que se aplica a la par o con jerarquía ${ }^{37}$ frente al derecho nacional que fuese pactado, cuya presencia incluso motiva al panel a basar la ratio de su decisión en la aplicación preeminente del derecho internacional frente a las normas disponibles. En Wena Hotels, se rebatió lo considerado por el panel en Klockner y se reivindicó su autonomía y aplicabilidad ${ }^{38}$ en el procedimiento de anulación, de nuevo en este caso, se resalta la presencia de un internacionalista latinoamericano en el panel, el chileno Francisco Orrego Vicuña:

38. Este debate pone de manifiesto las diversas opiniones expresadas sobre el papel del derecho internacional en el contexto del artículo 42 (1). La opinión académica, los escritos autorizados y algunas decisiones del CIADI se han ocupado de este asunto. Algunos puntos de vista han defendido un amplio papel del derecho internacional, que incluye no solo las normas contenidas en los tratados, sino también la definición bastante amplia de las fuentes contenidas en el Artículo 38 (1) del Estatuto de la Corte Internacional de Justicia. Otros puntos de vista han expresado que el derecho internacional esta solo llamado a complementar el derecho interno aplicable en caso de existencia de lagunas. En Klockner I, el Comité ad hoc introdujo el concepto de derecho internacional como un complemento del derecho aplicable en caso de lagunas y como correctivo en caso de que el derecho interno aplicable no se ajuste en todos los puntos a los principios del derecho internacional. También existe la opinión de que el derecho internacional ha de tener una función de control del derecho interno aplicable en la medida en que exista una colisión entre dicho derecho y las normas fundamentales del derecho internacional enunciadas en el concepto de jus cogens" 39 .

39. Algunas de estas opiniones tienen en común el hecho de que tienen como objetivo restringir el papel del derecho internacional y resaltar el del derecho del Estado receptor. A la inversa, el punto de vista que exige una aplicación amplia del derecho internacional apunta a restringir el papel del derecho del Estado receptor. Parece que no hay una sola respuesta en cuanto a cuál de estos enfoques es el correcto. Las circunstancias de cada caso pueden justificar una u otra solución. Sin embargo, la tarea de este Comité no es elaborar conclusiones precisas sobre este asunto, sino solo

\footnotetext{
35 Gaillard, 2003 , p. 399.

${ }^{36}$ Wena Hotels Limited c. Egipto. CIADI 2002. (ICSID Case No. ARB/98/4), Decision on Application for Annulment, Feb. 5, 2002. Para 38-40.

37 Petrova Georgieva, 2021. (Sobre el real alcance del concepto jerarquía de normas y tribunales entre lo nacional e internacional)

38 LEEKS, 2007.

${ }^{39}$ Wena Hotels Limited c. Egipto. CIADI 2002. (ICSID Case No. ARB/98/4), Decision on Application for Annulment, Feb. 5, 2002. Para 38-40.
} 
decidir si el Tribunal excedió manifiestamente sus poderes con respecto al Artículo 42 (1) del Convenio ICSID. Además, el uso de la palabra 'pudieren' en la segunda oración de esta disposición indica que el Convenio no traza una línea clara para la distinción del alcance respectivo del derecho internacional y del derecho interno y, en consecuencia, que esto tiene el efecto de conferir al Tribunal un cierto margen y facultades de interpretación ${ }^{40}$.

40. Lo que está claro es que el sentido y el significado de las negociaciones que condujeron a la segunda oración del Artículo 42 (1) permitieron que ambos órdenes legales tuvieran un papel. La ley del Estado receptor puede, de hecho, aplicarse en conjunción con el derecho internacional si esto está justificado. Así también el derecho internacional se puede aplicar por sí mismo si la regla apropiada se encuentra en este otro ámbito ${ }^{41}$.

El argumento elaborado por el panel en el laudo de anulación en Wena Hotels tiene el efecto de que en un caso determinado, las reglas del derecho internacional pueden ser el derecho aplicable de la misma manera que la ley del Estado receptor ${ }^{42}$. En un caso donde el tribunal ha revisado el derecho interno y las reglas y principios del derecho internacional, este último puede encontrar que para resolver la controversia existan dos reglas igualmente aplicables en cada sistema (nacional e internacional) y decidir que aplicará la regla del derecho internacional, sin necesidad de haber identificado una laguna en el derecho interno del Estado receptor.

En Wena Hotels, este fue el modo de aplicar un principio de derecho internacional, pues el Comité de anulación validó el laudo del Tribunal que mediante su interpretación del TBI y de las fuentes del Art. 38 del Estatuto de la CIJ, encontró el principio de derecho internacional de la compensación "rápida, adecuada y efectiva" que en ese caso no fue derivado de la aplicación del derecho interno que por el contrario, la evitaba ${ }^{43}$ :

51. The issue before this Committee, however, is a different one. Once the Tribunal decided to apply the IPPA to the dispute brought to it, and given the fact that this agreement does not contain provisions on the determination of interest as such, should the Tribunal have reverted to Egyptian law to this end or should it have resorted, as it did, to international law and related ICSID practice?

The option the Tribunal took was in the view of this Committee within the Tribunal's power. International law and ICSID practice, unlike the Egyptian Civil Code, offer a variety of

\footnotetext{
${ }^{40}$ Wena Hotels Limited c. Egipto. CIADI 2002. (ICSID Case No. ARB/98/4), Decision on Application for Annulment, Feb. 5, 2002. Para 38-40.

41 Wena Hotels Limited c. Egipto. CIADI 2002. (ICSID Case No. ARB/98/4), Decision on Application for Annulment, Feb. 5, 2002. Para 38-40.

42 PARra, 2007, pp. 1-12.

43 Gaillard, 2003, p. 399.
} 
alternatives that are compatible with those objectives. These alternatives include the compounding of interest in some cases ${ }^{44}$.

La decisión de Wena Hotels es fundamental en el progreso del CIADI hacia una aplicación preferente del derecho internacional y ha sido emulada por varios paneles, incluso en preferencia de una norma del Estado receptor. sectores de la doctrina han comentado el alcance del ejemplo establecido por Wena:

"El enfoque adoptado por el Comité de Wena ciertamente pone el arbitraje del CIADI en línea con otras formas de arbitraje internacional y reconoce la libertad de los tribunales del CIADI para encontrar en el derecho internacional, así como en el derecho del Estado anfitrión, las reglas apropiadas para la resolución de las disputas que se presentaron ante ellos. Reconocer esta flexibilidad, que está incorporada en la segunda oración del Artículo 42 (1), permitiría que el arbitraje del CIADI se desarrolle de acuerdo con la evolución de la función de adjudicación internacional los árbitros. (...)de las inversiones extranjeras. En ausencia de una elección del derecho aplicable y dependiendo de las circunstancias de cada caso, los árbitros deben tener la libertad de recurrir al derecho que consideren aplicable a este respecto. De hecho, sería una paradoja, en ese contexto, no reconocer plenamente el papel, consistente con la estructura y el lenguaje de la segunda oración del Artículo 42 (1), que el derecho internacional puede desempeñar en el arbitraje contemporáneo del CIADI" 45 .

\section{Costumbre Y JURISPRUdENCIA INTERNACIONAL INVOCADA COMO DERECHO APLICABLE EN ARBITRAJE INTERNACIONAL DE INVERSIONES}

Un conjunto particular de casos que ilustran de manera clara la directa necesidad de aplicar el derecho internacional mediante la costumbre internacional y la jurisprudencia de los tribunales internacionales, es el de los arbitrajes y procedimientos de anulación en los casos Continental ${ }^{46},{\mathrm{LG} \& E^{47}}^{4}$ Enron $^{48}$, Sempra ${ }^{49}$ y $\mathrm{CMS}^{50}$, procedimientos bajo el auspicio del TBI “ARG-USABIT” entre Argentina y Estados Unidos. Estos casos

${ }^{44}$ Wena Hotels Limited c. Egipto. CIADI 2002. (ICSID Case No. ARB/98/4), Decision on Application for Annulment, Feb. 5, 2002, para. 51.

45 Gaillard, 2003 , p. 373.

${ }^{46}$ Continental Casualty Company v. República Argentina, ICSID. Caso No. ARB/03/9. Laudo de 2008.

${ }^{47}$ LG\&E Energy Corp., LG\&E Capital Corp., LG\&E International, Inc. v. República Argentina, Caso ICSID n ${ }^{\circ}$ ARB/02/1. Decisión de 2007.

48 Enron Corporation y Ponderosa Assets, L.P. c. República Argentina, Caso ICSID n ARB/01/3. Decisión de 2007.

${ }^{49}$ Sempra Energy International c. República Argentina, Caso ICSID nº ARB/02/16. Decisión de 2007.

${ }^{50}$ CMS Gas-Transmission Company c. República Argentina, Caso ICSID, nº ARB/01/8. Decisión de 2007. 
aglomeran las peticiones de un conjunto de empresas del sector energético, protegidas como inversionistas extranjeros en Argentina, cuyos procedimientos produjeron varios laudos y sus correspondientes procedimientos de anulación produjeron enorme debate por la recepción de los argumentos de derecho internacional público invocados ante los paneles.

De los citados casos, son dos los elementos comunes que requerían la aplicación del derecho internacional público, sus fuentes y principios generales: el primero, es que las relaciones entre el inversionista y el Estado estaban cobijadas y desarrolladas directamente por el TBI y por pocos o ningún instrumento de derecho municipal, lo que llamaba a la directa aplicación del derecho de los tratados y otros elementos del derecho internacional. En segundo lugar, que la defensa invocada por Argentina al alegado incumplimiento de sus obligaciones, fue una institución propia del derecho internacional, una causal de exclusión de ilicitud ${ }^{51}$ propia del régimen de la responsabilidad internacional del Estado por hechos ilícitos, conocida como "estado de necesidad" (en este caso, invocada como un estado de necesidad económico) cuya fundamentación, codificada por la Comisión de Derecho Internacional de las Naciones Unidas, se basa en principios generales del derecho y en la costumbre internacional ${ }^{52}$.

En uno de estos casos contra Argentina ${ }^{53}$, para entender el concepto de estado de necesidad, el tribunal a cargo del laudo CMS aplicó la interpretación del concepto proveniente de la sentencia Gabcikovo-Nagymaros ${ }^{54}$ de la Corte Internacional de Justicia y decidió que al caso también le era aplicable directamente la costumbre internacional, bajo su codificación por la Comisión de Derecho Internacional (CDI) de las Naciones Unidas, en el Proyecto de Artículos sobre Responsabilidad internacional del Estado por hechos ilícitos, en su consagración del estado de necesidad en su Art. 25, usando como derecho aplicable al caso el test acumulativo de los elementos de la "necesidad", suplementando las expresiones generales del TBI, procedimiento por el que el tribunal verificaría la existencia o no del estado de necesidad mediante el cumplimiento de los requisitos de la misma según el derecho internacional público:

330. El Tribunal debe tener en cuenta otro aspecto importante. En el caso Gabcíkovo Nagymaros, la Corte Internacional de Justicia hizo referencia, de manera convincente, a la opinión de la Comisión de Derecho Internacional al efecto de que todas las condiciones que rigen el estado de necesidad deben cumplirse de una manera "acumulativa”.

331. En el presente caso, como se ha concluido, hay elementos de necesidad parcialmente presentes en algunos aspectos, pero cuando se analizan los distintos elementos, condiciones y límites en su conjunto, no puede concluirse que esos

51 Arévalo, 2015.

52 SLOANe, 2012, pp. 447-508.

53 Arévalo, 2017, pp. 469-512.

${ }^{54}$ International Court of Justice. "Case Concerning the Gabcikovo-Nagymaros Project (Hungary/Slovakia): Judgment of 25 September 1997”. ICJ Reports (1997): 7-84. 
elementos cumplen con la exigencia de un carácter acumulativo. Este hecho por sí mismo lleva a la conclusión inevitable de que no se han cumplido plenamente los requisitos relativos al estado de necesidad en la costumbre internacional como para permitir que se excluya la ilicitud de los actos ${ }^{55}$.

En este caso de aplicación de derecho internacional en arbitraje de inversiones mediante normas consuetudinarias, el comité de anulación, que validó el laudo en su decisión (Caso CIADI No. ARB/01/8, Procedimiento de anulación en el caso CMS) estableció tal y como sugería el caso Wena Hotels y el análisis de Gailliard, la concomitancia en la aplicación de las normas convencionales y pactadas (Art. XI del TBI) respecto de exclusión de ilicitud y el derecho internacional consuetudinario en la materia (Artículo 25 sobre estado de necesidad del Proyecto de la CDI $)^{56}$.

\section{PRincipios Generales Del DERECHO INVOCADOS COMO DERECHO INTERNACIONAL Y SU APLICACIÓN PARA DARLE CONTENIDO AL DERECHO SUSTANTIVO EN EL ARBITRAJE INTERNACIONAL DE LA INVERSIÓN EXTRANJERA}

Un lugar de especial relevancia para la aplicación de los principios generales del derecho en el arbitraje de inversión, es su función de dotar de contenido sustantivo a los estándares de protección internacionales, que suelen ser relativamente vagos y poco definidos por los tratados que protegen las inversiones, como ocurre con el "trato justo y equitativo", que ha sido dotado de contenido gracias a la invocación de principios generales del derecho y de su análisis comparado mediante nociones que son comunes a múltiples sistemas jurídicos ${ }^{57}$.

Un relevante ejemplo de esta invocación de principios generales del derecho es el caso Total, en donde el panel utiliza principios jurídicos, como la noción del respeto a la predictibilidad, el principio de las expectativas legítimas y el principio de razonabilidad, para darle contenido sustantivo a la obligación del tratado de protección de inversiones, vagamente estipulada, bajo la expresión de la protección de "la estabilidad" del inversionista.

122. De hecho, el caso más difícil es (como parte en la presente disputa) cuando la base de la invocación por parte de un inversionista del derecho a la estabilidad bajo una cláusula de trato justo y equitativo se basa en la legislación o regulación de carácter unilateral y general. En tales casos, las expectativas de los inversores están

${ }^{55}$ CMS Gas Transmission Company v. The Argentine Republic, ICSID Case No. ARB/01/8. Paras. $330-331$.

${ }^{56}$ CMS Gas Transmission Company v. Argentine Republic (ICSID Case No. ARB/01/8) (Annulment Proceeding) Decision Of The Ad Hoc Committee On The Application For Annulment Of The Argentine Republic. Paras. 130-131.

57 SCHILL, 2010. 
arraigadas en la regulación de una naturaleza normativa y administrativa que no está dirigida específicamente al inversionista relevante (...). 123 (....) La determinación de un incumplimiento de la norma requiere, por lo tanto, "una ponderación de las expectativas legítimas y razonables de la Demandante por un lado y el interés regulatorio legítimo del Demandado por el otro”. 127 Por lo tanto, una evaluación de la imparcialidad de La conducta del país anfitrión hacia un inversionista no se puede hacer de forma aislada, considerando solo sus relaciones bilaterales. El contexto de la evolución de la economía de acogida, la razonabilidad de los cambios normativos impugnados y su adecuación a la luz de un criterio de proporcionalidad también deben tenerse en cuenta ${ }^{58}$.

El trabajo de Stephan Schill ${ }^{59}$ respecto de los principios generales del derecho ${ }^{60}$ más aplicados en el arbitraje internacional de inversiones, ha identificado varios principios de derecho reconocidos tanto por el derecho internacional como en la práctica del derecho nacional, para darle contenido al estándar de "trato justo y equitativo", vagamente definido por los instrumentos internacionales para la protección de inversiones. Para Schill ${ }^{61}$, los tribunales arbitrales al momento de darle contenido al concepto de "trato justo y equitativo", hacen uso de principios generales del derecho universalmente reconocidos, emanados de la práctica nacional como de la aplicación del derecho internacional, entre ellos, Schill identifica el principio de previsibilidad y coherencia del derecho, el principio de la protección de las expectativas legítimas de los individuos, de clara estirpe administrativista, el debido proceso como principio general del derecho de la actividad judicial, el principio de transparencia, y el principio de proporcionalidad.

\section{Trato justo y equitativo como previsibilidad y coberencia del derecho}

Recientemente gran cantidad de laudos del CIADI han dado contenido al trato justo y equitativo, un estándar vagamente mencionado en los tratados, mediante las invocaciones del principio general del derecho de la previsibilidad y coherencia del derecho: laudos como CMS o Tecmed $^{62}$ han considerado que la falta de claridad del derecho nacional, el exceso de reglas vagas, pueden violar la protección del trato justo y equitativo concedida al inversionista extranjero. Esta coherencia también se ha predicado de los actos de la administración (principio de motivación), como ocurrió en el Tribunal en Tecmed que destacó la necesidad de coherencia en la toma de decisiones de las agencias del Estado para cumplir con un trato justo y equitativo. Asimismo, autores

\footnotetext{
58 Total S.A. c. The Argentine Republic, CIADI No. ARB/04/01 2010, paras. 122-127.

59 SCHILl, 2009.

60 SCHILl, 2012. Pp. 133-181.

61 Schill et al., 2009.

62 Tecnicas Medioambientales Tecmed S.A. v. The United Mexican States, ICSID Case No. ARB(AF)/00/2,
} Award of 29 May 2003. 
como Schill han comentado casos como MTD v. Chile ${ }^{63}$, donde el Tribunal encontró una violación del trato justo y equitativo debido a la incoherencia de la acción entre dos ramas del mismo Gobierno y sus autoridades, respecto de la misma inversión ${ }^{64}$.

El asunto del trato justo y equitativo es un excelente ejemplo de las complejas relaciones de las fuentes del derecho internacional público al momento de definir el alcance de las garantías materiales. Como lo indican autores como Roland Kläger, en cuanto al trato justo y equitativo, los paneles del CIADI han trasegado por opciones como solo aplicar su consagración según lo pactado en el tratado, la construcción de un estándar mínimo internacional mediante la doctrina, o su conceptualización desde la costumbre, los principios generales del derecho internacional y cuando se ha visto necesario, referencias al derecho doméstico, incluso llegando a casos donde la disputa ha girado en torno a si el panel debe entender el trato justo y equitativo solo según el tratado, o incluirle elementos materiales como la estabilidad del ambiente regulatorio, emanados de la costumbre internacional.

Así ocurrió en el caso $\mathrm{CMS}^{65}$, destacado como llamativo, como lo anota Kläger, pues fue el único que sobrevivió el procedimiento de anulación dentro de los casos de la crisis económica argentina y fue el que mayor fundamento en el derecho internacional público tuvo en estos procedimientos ${ }^{66}$. Esta profunda relación entre esta garantía material y su contenido emanado del derecho internacional público, en especial la costumbre, se sigue desarrollando en la actualidad, en laudos herederos de CMS en el CIADI como el laudo LG\&E ${ }^{67}$ o laudos de otros foros, como CEF Energía BEF v. Italia de 2019 en el Centro de Arbitraje de Estocolmo (SCC) ${ }^{68}$, donde el tribunal delimita el concepto de expectativa legítima mediante un detallado análisis de su significado en el derecho internacional y en otros laudos, más allá de lo consagrado en las normas nacionales o el tratado aplicable.

\section{Trato justo y equitativo desde la protección de las expectativas legítimas de los individuos y el debido proceso}

En casos como Saluka y Tecmed, los laudos han identificado el trato justo y equitativo como relacionado directamente al principio del respeto a las expectativas legítimas de los individuos, invocable como principio general del derecho, que en el ámbito de las inversiones, ha sido entendido por estos tribunales como la obligación de respetar las más esenciales razones y expectativas que motivaron a los inversionistas a efectuar

\footnotetext{
63 MTD Equity Sdn. Bhd. MTD Chile S.A. v. Republic of Chile, ICSID Case No. ARB/01/7. 2004.

${ }^{64}$ Schill et al., 2009.

${ }^{65}$ CMS Gas Transmissian Co. v. Argentina paras. 273-281.

66 KLÄGER, 2011, pp. 79.

${ }^{67}$ LG\&E Energy Corp., LG\&E Capital Corp., and LG\&E International, Inc .v. Argentine Republic, ICSID Case No. ARB/02/1. 2007 para. 46.

${ }^{68}$ CEF Energia BV v. Italian Republic, SCC Case No. 158/2015 Award 2019. paras. 183-235.
} 
su inversión y que originalmente fueron alimentadas por la conducta del Estado, que no pueden verse afectadas por posteriores arbitrariedades ${ }^{69}$.

En la práctica de los tribunales arbitrales y su identificación de principios generales del derecho para darle contenido a las protecciones contempladas en los tratados, el trato equitativo está identificado con el principio jurídico de la correcta administración de justicia y el debido proceso. El caso Waste Management v. México, por ejemplo, define expresamente que la violación del trato justo y equitativo puede emanar de la falta de debido proceso que lleve a errores judiciales, como también la denegación de justicia y la imposibilidad de obtener un debido proceso en sede administrativa ${ }^{70}$.

A su vez, de nuevo en el caso Tecmed, el tribunal considera que la transparencia de las autoridades es un elemento fundamental del trato justo y equitativo; la actitud ambigua del Estado con la información, la falta de motivación de las decisiones, entre otros, constituye una violación del trato justo y equitativo:

154 (...) Como parte de tales expectativas, aquel cuenta con que el Estado receptor de la inversión se conducirá de manera coherente, desprovista de ambigüedades y transparente en sus relaciones con el inversor extranjero, de manera que este pueda conocer de manera anticipada, para planificar sus actividades y ajustar su conducta, no solo las normas o reglamentaciones que regirán tales actividades, sino también las políticas perseguidas por tal normativa y las prácticas o directivas administrativas que les son relevantes. Un accionar del Estado ajustado a tales criterios es, pues, esperable, tanto en relación con las pautas de conducta, directivas o requerimientos impartidos, o de las resoluciones dictadas de conformidad con las mismas, cuanto con las razones y finalidades que las subyacen. El inversor extranjero también espera que el Estado receptor actuará de manera no contradictoria; es decir, entre otras cosas, sin revertir de manera arbitraria decisiones o aprobaciones anteriores o preexistentes emanadas del Estado en las que el inversor confió y basó la asunción de sus compromisos y la planificación y puesta en marcha de su operación económica y comercial. El inversor igualmente confía que el Estado utilizará los instrumentos legales que rigen la actuación del inversor o la inversión de conformidad con la función típicamente previsible de tales instrumentos, y en todo caso nunca para privar al inversor de su inversión sin compensación. En realidad, la no observancia por el Estado receptor de la inversión de las pautas apuntadas en su conducta relativa al inversor extranjero o sus inversiones perjudica la posibilidad de este, tanto de apreciar el nivel de trato y protección realmente brindado por el Estado receptor, como de determinar hasta qué punto dicho Estado observa un comportamiento acorde con la garantía de trato justo y equitativo ${ }^{71}$.

${ }^{69}$ SCHILl et al., 2009. p. 22.

${ }^{70}$ SCHILL, 2012, pp. 133-181.

71 Técnicas Medioambientales Tecmed, S.A. v. The United Mexican States, ICSID Case No. ARB (AF)/00/2. Laudo 2003, paras. 154-155 


\section{Proporcionalidad en las cargas públicas y trato justo y equitativo}

En los laudos Saluka (UNCITRAL) y Tecmed, los tribunales arbitrales han dado contenido al trato justo y equitativo mediante el principio de proporcionalidad, entendido en los sistemas jurídicos nacionales como la prudencia y medida en que las intromisiones del Estado y sus regulaciones no afecten de forma desmedida a las actividades del inversionista ${ }^{72}$.

122. Descartada la exclusión a priori del posible encuadramiento de actos o medidas de naturaleza regulatoria de la categoría de actos expropiatorios, además del impacto económico negativo causado por tales actos o medidas, el Tribunal Arbitral estima apropiado considerar, para determinar si dicho encuadramiento procede, la proporcionalidad de dichos actos o medidas con las exigencias del interés público presuntamente tutelado a través de los mismos y la protección legalmente debida al inversor en relación con su inversión, sin olvidar que la magnitud de dicho impacto juega un rol de peso al juzgar acerca de dicha proporcionalidad ${ }^{73}$.

4. Principios generales del derecho en materia de reparaciones aplicados en el derecho internacional de la inversión extranjera

Finalmente, la aplicabilidad de los principios generales del derecho y de las fuentes del derecho internacional en el arbitraje de inversiones también ocurre en el ámbito de las reparaciones, una vez establecida la responsabilidad internacional del Estado por el tribunal arbitral. Los laudos del CIADI aplican de manera constante los principios de reparación integral, tal y como son expresados en el caso fábrica de Chorzow y por la Comisión de Derecho Internacional en sus artículos acerca de responsabilidad internacional, en virtud de la aplicación de la noción de reparación integral mediante los criterios de compensación, restitución y satisfacción.

Laudos como Metalclad, reafirman la aplicabilidad en el arbitraje internacional de inversiones, para efectos de la reparación, del principio de reparación integral, incluyendo daño emergente y lucro cesante.

122. (...) De manera similar, en el caso Biloune (véase más arriba), el Tribunal concluyó que el valor de los bienes expropiados era igual al valor de la inversión en dichos bienes efectuada por el demandante. Si bien reconoció la validez del principio de que para valuar los bienes expropiados debería tomarse en cuenta el lucro cesante, el Tribunal no concedió compensación alguna por lucro cesante porque los demandantes no pudieron estimarlo de manera realista. En ese caso,

\footnotetext{
72 SCHILl et al., 2009.

73 Técnicas Medioambientales Tecmed, S.A. v. The United Mexican States, ICSID Case No. ARB
} (AF)/00/2. Laudo 2003, para. 122. 
como en el que nos ocupa, la expropiación tuvo lugar cuando el proyecto todavía no funcionaba ni generaba ingresos (Biloune, 95 I.L.R., págs. 228-229). El laudo que concede a Metalclad el costo de su inversión en el confinamiento es congruente con los principios establecidos en Chorzow Factory (Reclamo de indemnización) (Fondos), Alemania c. Polonia, P.C.I.J. Serie A, No. 17 (1928), pág. 47, a saber, cuando el Estado hubiera incumplido sus obligaciones, cualquier laudo favorable al demandante debería, en la medida de lo posible, borrar todas las consecuencias del acto ilegítimo y restablecer la situación que probablemente imperaría de no haberse cometido dicho acto (el statu quo ante) ${ }^{74}$.

\section{CONCLUSIÓN}

Tras analizar la evolución de los laudos del CIADI en materia de su aplicación de distintas fuentes del derecho internacional público, es posible concluir que los paneles en la actualidad han adoptado la interpretación de que el Art. 42 permite la invocación y la aplicabilidad de las costumbre y principios reconocidos por el derecho internacional público a los procedimientos de arbitraje internacional de inversiones de forma directa y autónoma, sin ser simplemente normas supletivas para llenar vacíos y lagunas en el derecho del Estado receptor, el instrumento de inversiones o en la elección del derecho aplicable realizada por las partes. Los casos analizados demuestran que los principios generales del derecho, como el debido proceso, transparencia, o expectativas legítimas, son cada vez más invocados como derecho internacional público, para darle contenido a los instrumentos de protección de inversiones, especialmente para darle carácter sustantivo a conceptos tan amplios como "trato justo y equitativo". Por último, los casos analizados demuestran que los principios generales del derecho internacional en materia de reparación integral, reconocidos en la jurisprudencia de la Corte Internacional de Justicia, constituyen el concepto de reparación utilizado por los laudos de los tribunales arbitrales del CIADI frente a los hechos ilícitos del Estado que vulneran las protecciones convencionales concedidas a los inversionistas extranjeros.

\section{BIBLIOGRAFÍA}

\section{Libros, capítulos y artículos de Revista indexada}

Alvarez, José E, 2011: The public international law regime governing international investment. Vol. 344. Martinus Nijhoff Publishers.

Arévalo, Walter, García Matamoros, Laura, 2017: "El estado de necesidad en el arbitraje de inversión: su invocación consuetudinaria y convencional en los arbitrajes Enron, Sempra,

${ }^{74}$ Metalclad Corporation v. The United Mexican States, ICSID Case No. ARB(AF)/97/1. Award. 2000, para. 122 . 
CMS, LG\&E y Continental ante el Centro Internacional de Arreglo de Diferencias relativas a Inversiones (CIADI)". Anuario Mexicano de derecho internacional 17. Pp. 469-512.

Arévalo, Walter, García Matamoros, Laura, 2016: "Arbitraje de inversión. Definición y aspectos procesales relevantes: principios generales y desarrollos en el CIADI” En. García, Laura. Aljure, Antonio. Estudios contemporáneos de derecho internacional privado. Legis Editores, pp. 243-278.

ArÉvalo, Walter, 2015: "Responsabilidad internacional del Estado por hechos internacionalmente ilícitos: las causales de exclusión de ilicitud, su contenido y escenarios de aplicación”. Derecho internacional: varias visiones de un maestro. Liber amicorum en Homenaje a Marco Gerardo Monroy Cabra. Editorial Universidad del Rosario. Bogotá.

Arévalo, Walter, 2020. "Fuentes del derecho internacional, principios generales del derecho y su aplicación en el derecho internacional de la inversión extranjera”. En. Prieto Enrique, Urueña, Rene. Debates contemporáneos de derecho internacional económico: una mirada desde Colombia. Universidad del Rosario.

Arévalo, Walter, 2019: Manual de Derecho Internacional Público. Tirant Lo Blanch.

Christian Tietje, 2016: "Investor-State Arbitration as Part of the International Rule of Law", Völkerrechtsblog, 4 Julio 2016, doi: 10.17176/20180220-231424.

Chunwumerije, Okezie, 1997: "International law and Article 42 of the ICSID Convention". Journal of International Arbitration 14.3, pp. 79-101.

Delaney, Jo, 2007: “'Expropriation' and 'Fair and Equitable Treatment' Standards in Recent ICSID Jurisprudence". The International Convention on the Settlement of Investment Disputes (ICSID). Nomos Verlagsgesellschaft mbH \& Co. KG.

Franck, Susan D. 2004: "The Legitimacy Crisis in Investment Treaty Arbitration: Privatizing Publlic International Law through Inconsistent Decisions”. Fordham L. Rev. 73, pp. 1521.

Fry, James D, 2007: "International Human Rights Law in Investment Arbitration: Evidence of International Law's Unity". Duke Journal of Comparative E International Law. 18, pp. 77.

Gaillard, Emmanuel, Yas Banifatemi, 2003: "The Meaning of" and" in Article 42 (1), Second Sentence, of the Washington Convention: The Role of International Law in the ICSID Choice of Law Process". ICSID REVIEW 18, pp. 375-411.

Gazzini, Tarcisio, Eric De Brabandere, eds, 2012: International Investment Law. The Sources of Rights and Obligations. Martinus Nijhoff Publishers.

KLÄGER, Roland, 2011: "Fair and Equitable Treatment", in International Investment Law. Vol. 83. Cambridge University Press,

LeEks, Annie, 2007: "The relationship between bilateral investment treaty arbitration and the wider corpus of international law: the ICSID approach". U. Toronto Fac. L. Rev. 65. 1.

LIM, Chin Leng, Jean Ho, Martins Paparinskis.2018: International investment law and arbitration: commentary, awards and other materials. Cambridge University Press, 2018, rev. 2021.

Lowenfeld, Andreas F, 2003: "Investment agreements and international law". Columbia Journal of Transnational Law. 42, pp. 123.

McLaChlan, Campbell, 2008: "Investment treaties and general international law". International E Comparative Law Quarterly 57.2, pp. 361-401.

PArra, Antonio R, 2008: “Applicable Law in Investor-State Arbitration”. Contemporary Issues in International Arbitration and Mediation: The Fordham Papers. Brill Nijhoff, pp. 1-12.

Petrova Georgieva, Virdzhiniya, 2021. "Hierarchy between Domestic and International Tribunals: Utopia or Near Future?”. Anuario Colombiano de Derecho Internacional (acdi), pp. 173-223.

SALACUSE, Jeswald. 2013. The three laws of international investment: national, contractual, and international frameworks for foreign capital. Oxford University Press, p. 315.

Schill, Stephan, ed. 2010: International investment law and comparative public law. Oxford University Press. 
SCHILL, Stephan, et al. 2008; General Public International Law and International Investment Law: A Research Sketch on Selected Issues.

Schreuer, C, 2009: The ICSID Convention: A Commentary (Segunda ed.). Cambridge: Cambridge University Press. Pp. 607.

SChreuer, Christoph, 2005; "Calvo's Grandchildren: The Return of Local Remedies in Investment Arbitration". The Law and Practice of International Courts and Tribunals 4.1, pp. 1-17.

SCHREUER, Christoph, 2007; "The relevance of public international law in international commercial arbitration: investment disputes”. Working Paper. www.univie.ac.at/intlaw/wordpress/ pdf/81_csunpublpaper_ 1 .

SlOANE, Robert D, 2012: "On the use and abuse of necessity in the law of state responsibility". American Journal of International Law 106.3. pp. 447-508.

Verhoosel, Gaëtan, 2008: "Annulment and enforcement review of treaty awards: to ICSID or not to ICSID”. ICSID review 23.1, pp. 119-154.

\section{Jurisprudencia internacional}

Ceskoslovenska Obchodni Banka, a.s. v. The Slovak Republic ICSID Case No. ARB/97/4 Award 2004.

CEF Energia BV v. Italian Republic, SCC Case No. 158/2015 Award 2019. paras. 183-235

CMS Gas Transmission Company v. Argentine Republic (ICSID Case No. ARB/01/8) (Annulment Proceeding) Decision Of The Ad Hoc Committee On The Application For Annulment Of The Argentine Republic. Sept.2007.

Continental Casualty Company v. The Argentine Republic, ICSID. Caso No. ARB/03/9. Award. 2008.

Enron Corporation y Ponderosa Assets, L.P. c. República Argentina, Caso ICSID no ARB/01/3Award 2007.

ICJ, North Sea Continental Shelf cases, Reports 1969, p. 42, para 72.

International Court of Justice. "Case Concerning the Gabcikovo-Nagymaros Project (Hungary/ Slovakia): Judgment of 25 September 1997”. ICJ Reports (1997): 7-84.

Klockner c. Cameroon, Ad Hoc Committee Decision, 19852 ICSID Rep. 95 (1994) para 122. Award 1985.

LG\&E Energy Corp., LG\&E Capital Corp., and LG\&E International, Inc .v. Argentine Republic, ICSID Case No. ARB/02/1. 2007 para. 46Metalclad Corporation v. The United Mexican States, ICSID Case No. ARB(AF)/97/1. Award. 2000.

MTD Equity Sdn. Bhd. MTD Chile S.A. v. Republic of Chile, ICSID Case No. ARB/01/7. Award 2004.

Sempra Energy International c. República Argentina, Caso ICSID nº ARB/02/16 Award.2007.

Southern Pacific Properties (Middle East) Limited v. Arab Republic of Egypt ICSID Case No. ARB/84/3 Award 1990.

TÉCNICAs Medioambientales Tecmed, S.A. v. The United Mexican States, ICSID Case No. ARB (AF)/00/2. Award. 2003.

Total S.A. c. The Argentine Republic, CIADI No. ARB/04/01 Award. 2010.

Wena Hotels Limited c. Egipto. CIADI 2002. (ICSID Case No. ARB/98/4), Decision on Application for Annulment, Feb. 5, 2002. Para 38-40. 